\title{
İzmir-Bornova'da Gebelerin Ağız-Diş Sağlığı Hizmeti Gereksinimi Ve Bu Hizmetlerden Yararlanma Düzeyinin Sosyoekonomik Değişkenlerle İlişkisi*
}

\section{Ayşe Nur USTURALI MUT ${ }^{1}$, Zeliha Aslı ÖCEK ${ }^{1}$, Ummahan YÜCEL ${ }^{2}$, Meltem ÇiÇEKLİOĞLU ${ }^{1}$, Ece EDEN ${ }^{3}$}

${ }^{1}$ Ege Üniversitesi Tıp Fakültesi, Halk Sağlığı Anabilim Dalı

2Ege Üniversitesi İmir Atatürk Sağlık Yüksekokulu, Ebelik Bölümü

${ }^{3}$ Ege Üniversitesi Diş Hekimliği Fakültesi, Pedodonti Anabilim Dalı

\section{Ayşe Nur USTURALI MUT}

Ege Üniversitesi Tıp Fakültesi

Halk Sağlı̆̆ı AD

35100, Bornova, İZMiR
Öz

Amaç: İzmir-Bornova'nın üç semtinde yaşayan, 2013 Nisan-Haziran ayları arasında gebe olan kadınların ağız-diş sağlığı hizmeti gereksinimlerinin, bu hizmetlerden yararlanma düzeylerinin ve bu düzeyin bir dizi sosyoekonomik değişken ile ilişkisinin değerlendirilmesi hedeflenmiştir.

Yöntemler: Bu kesitsel araştırmada 2013 Nisan-Haziran aylarında Bornova'nın Mevlana, Naldöken ve Altındağ semtlerinde yaşayan tüm gebelere $(n=289)$ ulaşılması hedeflenmiş, ancak \% 85,8'i ( $\mathrm{n}=248)$ çalışmaya katılmıştır. Araştırmada diş hekimi muayenelerinin yanı sıra anket uygulanmıştır. Ağız-diş sağlığı gereksinimi iki şekilde tanımlanmıştır; 1) diş muayenesinde çürük ve/veya protez gerektiren eksik diş ve / veya dişeti hastalığı varlığı, 2) algılanan gereksinim. Hizmetlerden yararlanma düzeyinin sorgulanması amacıyla, kadınların son bir yıl içinde ve gebeliklerinde diş hekimine gidip gitmedikleri saptanmıştır. Bağımsız değişkenler sosyodemografik-ekonomik durum, genel sağlık düzeyi ve ağız-diş sağlığı düzeyi ile ilgili öz değerlendirme olarak gruplanmiştır.

Bulgular: Çürük ve/veya protez gerektiren eksik dişe bağlı olarak gebelerin \%90,7'sinin, dişeti hastalığı nedeniyle de \%56,9'unun tedavi gereksinimi olduğu belirlenmiştir. Buna göre, gebelerin \%94,4'ü hizmete gereksinim duymaktadır. Bu gebelerin \%39,3'ü son bir yıl içinde ve \%6'sı gebeliği sırasında diş hekimine gidebilmiştir. Geliri asgari ücretin üstünde olan gebelerde son bir yılda diş hekimi ziyareti olasılığı 2,05 kat yüksek bulunmuştur. Gebelerin sadece \%31'i kendisine bir diş hekimi tarafından dişlerinin nasıl temizlenmesi gerektiğinin gösterildiğini ve \%7,3’ü herhangi bir sağlık çalışanı tarafından gebelik dönemine özel ağız-diş sağlı̆̆ı sorunları hakkında bilgilendirildiğini ifade etmiştir.

Sonuç: Araştırma grubunun ağız-diş sağlığı gereksinimleri büyük oranda karşılanmamaktadır ve diş hekimliği hizmetlerinden yararlanma açısından gelir düzeyine bağlı 
bir eşitsizlik vardır.

Anahtar sözcükler: Gebe, ağız-diş sağlığı, gereksinim, hizmet kullanımı

ABSTRACT

Objective: The aim was to identify the dental service needs of pregnant women living in three districts of Bornova-İzmir. It was also aimed to determine the level of utilization of these services and factors related to the utilization.

Methods: In this cross-sectional study, it was targeted to reach all pregnant women living in the Mevlana, Naldöken and Altındağ districts of Bornova between April and June $2013(n=289)$, but $85.8 \%(n=248)$ participated. In addition to dental examinations, a questionnaire was administered. Dental service needs were defined in two ways: 1) the presence of decay and/or missing teeth and/or gum disease requiring dental prosthesis at examination, 2) perceived requirement. In order to detect the level of utilization of services, women having received dental treatment in the last year and during pregnancy were determined. The independent variables were grouped into sociodemographic-economic situation, general level of health and self-assessment of level of dental health.

Results: It was found that $90.7 \%$ of participants required treatment for decay and/or missing teeth needing dental prosthetics and $56.9 \%$ needed treatment for gum disease. According to this, $94.4 \%$ of the study population needed dental services. The percentages of the women who had visited a dentist in the last year and had visited a dentist during their pregnancy were $39.3 \%$ and $6 \%$ respectively. It was found that the likelihood of having visited a dentist in the last year was 2.05 times higher among participants whose income was above the minimum wage. The percentage of women who were instructed by a dentist on brushing was $31 \%$ and only $7.3 \%$ of participants were informed by a health care worker on pregnancy-specific dental problems.

Conclusion: The dental health needs of the study group were largely unmet and there were inequalities according to level of income in the extent to which pregnant women benefited from dental services.

Keywords: Pregnancy, dental health, need, utilization of services

A ğız-diş hastalıkları ülkemizde en sık karşılaşılan sağlık sorunları arasında yer almakta, anne adayları ise bu sorunlar açısından çok özel bir risk grubunu oluşturmaktadır (1). Gebelik boyunca gelişen hormonal ve vasküler değişikliklerin, özellikle de östrojen düzeyindeki artışın diş eti dokularında hiperemi, enflamasyon, kolay kanama ve artmış duyarlılık ile karakterize bir tabloya yol açtığı ve bunun sonucunda bakteriyel enfeksiyon riskinin, dolayısıyla da diş eti hastalıklarına yatkınlığın arttığı bilinmektedir (2-5). Farklı ülkelerde yapılan çalışmaların sonuçları değerlendirildiğinde, yaklaşık olarak her üç anne adayından ikisinde gebelik periodontitisi geliştiği görülmektedir (5-8). Gebelik dönemindeki ağız-diş sağlı̆̆1 sorunları annenin yaşam kalitesini ve genel sağlık düzeyini etkilemekte, ayrıca etkileri sadece anne ile sınırlı kalmamaktadır. Pek çok çalışma periodontal hastalığın erken doğum ve düşük doğum ağırlığı için bir risk faktörü olduğunu göstermiş, Bogges ve ark. preeklampsi riskinde de bir artış olduğunu bildirmiştir (2,9-15).

Anne adaylarının ağı-diş sağlığını değerlendiren çalışmalarda öğrenim, gelir, sosyal sınıf vb değişkenler açısından dezavantajlı gebelerin gerek diş eti hastalıklarından gerekse diğer diş sağlı̆̆ı sorunlarından daha yoğun bir şekilde etkilendikleri görülmüştür (3,16-18). Sosyal, ekonomik ve çevresel faktörlerin ağı-diş sağlığı üzerindeki etkisini yansıtan kanıtlar dikkate alınırsa bu belirleyiciler açısından yaşanan eşitsizliklerin gebelik döneminde de söz konusu olması beklenen bir durumdur (19-23). Ayrıca ağız-diş sağlığı ile genel sağlık düzeyi arasındaki ilişkinin, yoksullarda toplumun genelinden daha güçlü bir şekilde gözlenmesi nedeniyle yoksul gebelerin çok daha ciddi bir tehlike ile karşı karşıya olduğu düşünülebilir (24).

Bugüne kadar elde edilen kantlara göre gebelik dönemindeki ağız-diş sağlığı sorunlarını kontrol etmeye ve eşitsizlikleri azaltmaya yönelik çalışmaların en önemli bileşeni diş hekimliği hizmetlerinden yararlanmanın sağlanmasıdır (25). Profesyonel plak temizliği ve ağız hijyeni eğitiminin gingival enflamasyon ve kanamayı azaltarak gebelikteki diş eti hastalığı riskini en düşük düzeye indirebildiği bildirilmekte ve bu nedenle gebeikleri boyunca tüm kadınların ağız sağlığının en az bir kez diş hekimi tarafından kontrol edilmesi ve ağız hijyeni 
bakımı uygulanması önerilmektedir (2,26-30). Bu açıdan ülkemizde tüm gebeler özellikle de yoksul gebeler arasında diş hekimliği hizmetlerinden yararlanım düzeyini saptayan ve bunların karşılanmasının önündeki engelleri ortaya koyacak çalışmalara büyük gereksinim duyulmaktadır.

Bu çalışma İzmir-Bornova Belediyesi'nin sosyal hizmet programı yürüttüğü üç semtte, gebelerin ve çocukların ağız-diş sağlığını geliştirmek amacıyla gerçekleştirilen bir proje kapsamında yürütülmüştür. Çalışma, bu semtlerde yaşayan ve 2013 yılı Nisan ve Haziran ayları arasında gebe olan kadınların ağız-diş sağlığı hizmetlerine duydukları gereksinim düzeyinin belirlenmesi amacıyla uygulanmıştır. Ayrıca araştırma grubunun diş hekimliği hizmetlerinden yararlanma düzeyinin ve bu düzeyin bir dizi sosyoekonomik değişken ile ilişkisinin değerlendirilmesi hedeflenmiştir.

\section{YÖNTEM}

\section{Araştırma Grubu}

Kesitsel nitelikteki bu çalışmanın evrenini İzmirBornova Belediyesi'nin sosyal hizmet programı yürüttüğü Mevlana, Naldöken ve Altındağ semtlerinde yaşayan ve 2013 yılı Nisan - Haziran aylarında gebeliğinin herhangi bir haftasında olan kadınlar oluşturmuştur. Bornova Belediyesi'nin alan çalışmalarını yürüten, evde gebe izlemi hizmeti veren ve gerektiğinde gebelerin saptanması için birinci basamak kurumlarından da bilgi alan ebelerden, bu semtlerde toplam 289 gebe bulunduğu öğrenilmiş ve bu gebelerin tümüne ulaşılması hedeflenmiştir. Anne adayları belediyenin ebeleri aracılığıyla semtlerinde bulunan kültür merkezlerine ağız-diş sağlığı eğitimi almak ve diş hekimleri tarafından muayene edilmek üzere davet edilmiştir. Kültür merkezlerine 253 gebe gelmiş, Türkçe bilmeyen ve yanında çeviri konusunda bir yardımcı bulunmayan üç kadın ve iletişim sorunu yaşanan iki kadın çalışma kapsamına alınmamıştır. Gebelerin \%85,8'i (248) Bilgilendirilmiş Gönüllü Olur Formu'nu imzalayarak çalışmaya katılmıştır.

Araştırma için etik onay Ege Üniversitesi Tıp Fakültesi Klinik Araştırmalar Etik Kurulu'ndan alınmıştır (B.30.2.EGE.0.20.05.00/OY).

\section{Değişkenler ve Veri Toplama}

Bu çalışmanın bağımlı değişkenleri ağız-diş sağlığı hizmeti gereksinimi ve diş hekimliği hizmetlerinden yararlanma düzeyidir. Hizmet gereksinimi iki şekilde tanımlanmıştır. İlk tanım diş hekimi muayenesi sonucunda anne adayının ağzında çürük, protez gerektiren eksik diş ve/veya diş eti hastalığı (gingivitis veya periodontitis) saptanmış olmasına dayanmaktadır. İkinci tanım ise anne adaylarının gebeliğinin başından itibaren dişleriyle ilgili bir sorun yaşayıp yaşamadığını temel almaktadır. Hizmetlerden yararlanma düzeyinin sorgulanması amacıyla, kadınların son bir yıl içinde ve gebeliklerinde diş hekimine gidip gitmedikleri saptanmıştır. Gebeliği boyunca dişleriyle ilgili bir sorun yaşadığını, ama diş hekimine gitmediğini belirten kadınlardan bu durumun nedenini de belirtmeleri istenmiştir. Anne adaylarının ağız-diş sağlığı eğitimi amaçlı hizmetlerden yararlanma düzeyi de sorgulanmış, herhangi bir sağlık çalışanından gebelik ve çocukluk döneminde ağız-diş sağlığı bakımı hakkında eğitim almış olan ve doğru diş fırçalama tekniği hakkında bir diş hekimi tarafından bilgilendirilmiş olan katılımcı yüzdesi saptanmıştır. Ayrıca araştırma grubuna tüm yaşamları boyunca kendileri için ve mevcut gebeliği dışında çocuğu olanlara çocukları için en az bir kez diş hekiminden hizmet alıp almadıkları sorulmuştur.

Çalışmanın bağımsız değişkenleri sosyodemografik ve ekonomik durum, genel sağlık düzeyi ve ağız-diş sağlığı düzeyi ile ilgili öz değerlendirme olarak gruplanmıştır. Sosyodemografik ve ekonomik durum başlığı altında yaş, medeni durum, çocuk sayısı, öğrenim durumu, eşin öğrenim durumu, İzmir'de yaşama süresi, İzmir'e gelmeden önce en uzun süre yaşanılan yer, anadil, meslek, eşin mesleği, sosyal sınıf, aile yapısı, sosyal güvence ve sağlık güvencesi tipi, evde yaşayan kişi sayısı, evdeki oda sayısı ve gelir düzeyi yer almaktadır. Gelir düzeyinin belirlenmesi amacıyla haneye giren toplam aylık gelir sorulmuş ve araştırma tarihindeki asgari ücret miktarına göre; asgari ücretin altında ve asgari ücret ve üzerinde olarak gruplanmıştır. Sosyal sınıf, hane reisinin işine göre belirlenmiştir. Bu değişken; kendi hesabına çalışanlar (yanında işçi çalıştırmayanlar), işverenler (yanında işçi çalıştıranlar), beyaz yakalılar (kafa emeği ile üretim yapanlar), mavi yakalılar (daha çok el emeği ile üretim yapanlar), işsiz ve 
marjinaller (gelir getirici işi olmayanlar, sürekli olmayan ve kayıt dışı işlerde çalışanlar) olmak üzere beş grupta incelenmiştir $(31,32)$. Genel sağlık düzeyi ile ilgili olarak gebelik haftasının yanı sıra, kronik hastalık sorgulanmıştır. Katılımcıların gebelik öncesinde ve gebelik sırasında olmak üzere ağız-diş sağlığı ile ilgili öz değerlendirmesinin belirlenmesi amacıyla beşli Likert Skalası (çok kötü, kötü, orta, iyi, çok iyi) kullanılmıştır. Yukarıda sıralanan değişkenleri belirlemek amacıyla bir anket hazırlanmış, Bornova-25 nolu Mevlana ASM'ye kayıtlı ve araştırma grubunda yer almayan 15 gebede anketin pilot uygulaması yapılarak, gerekli değişiklikler gerçekleştirilmiştir.

Çalışmanın verileri Bornova Belediyesi Kültür Merkezleri'nde gerçekleştirilen ağız-diş sağlı̆̆ etkinliklerinin hemen öncesinde toplanmıştır. Toplam 13 iş günü süren çalışma boyunca araştırma ekibi tarafından yüz-yüze görüşme tekniğiyle anket uygulanmıştır. Anket uygulamasının ardından proje ekibine gönüllü olarak katılan diş hekimleri bu çalışma için oluşturulmuş olan muayene odalarında anne adaylarının diş eti hastalıklarını, çürük ve eksik dişlerini bir forma aktarmıştır. Ayrıca doğru diş fırçalama tekniği hakkında birebir eğitim alan anne adayları "gebelik döneminde ağız-diş sağlı̆̆g" başlıklı bir seminere katılmıştır. İleri düzeyde diş eti hastalığı olan gebelere Ege Üniversitesi Diş Hekimliği Fakültesi'nde tedavi edilmeleri için randevu verilmiş, diğer sorunlar için Bornova Belediyesi'nin diş hekimliği kliniğinden hizmet alınabileceği belirtilmiştir.

\section{İSTATISTIKSEL ANALIZ}

İstatistiksel analizlerde $p<0,05$ anlamlılık düzeyi olarak belirlenmiş, bağımlı ve bağımsız değişkenler arasındaki ilişkiler önce ki-kare testi, ardından ileri aşamalı (Forward stepwise) lojistik regresyon analizi aracılığı ile değerlendirilmiştir. Kadınların gebelik öncesinde ve gebelik sırasında dişleriyle ilgili öz-değerlendirmeleri marjinal homojenite testi ile karşılaştırılmıştır.

\section{BULGULAR}

Çalışmaya katılan anne adaylarının \%77'sı ilk iki trimesterdedir ve yaş ortalamaları 27,3 \pm 5,35 (en düşük: 18 en yüksek: 43) olarak hesaplanmıştır. Tablo I'de araştırma grubunun tanımlayıcı değişkenlere göre dağılımı sunulmuştur. Buna göre yaklaşık her yedi kadından biri okuryazar değilken, her beş kadından biri de ilkokul mezunu değildir. İlkokul ve altında öğrenim durumuna sahip olan eş oranı \%52,8'dir. Kadınların \%25,8'i anadilinin Türkçe olmadığını söylemiş, bunların \%12,5'i de dil sorunu needniyle sağlık hizmetine erişimde güçlük yaşadığını aktarmıştır. Yaklaşık her dört kadından birinin sosyal güvencesi bulunmamaktadır. Sosyal sınıf grupları içinde \%63,7 ile mavi yakalı-niteliksiz hizmet işçisi sınıfı çoğunluğu oluşturmaktadır. Anne adaylarının \%35,1'inin aylık hane gelirlerinin asgari ücretin altında olduğu saptanmıştır (Tablo I). Çalışma grubunun \%19'unun doktor tarafından tanı konulmuş bir kronik hastalığının bulunduğu belirlenmiştir.

Tablo II'de anne adaylarının gebe kalmadan önceki ve gebelik sırasındaki ağı-diş sağlı̆̆ ile ilgili öz değerlendirmeleri karşılaştırılmıştır. Gebe kalmadan önceki ağız-diş sağlığı düzeyini "çok iyi-iyi" olarak değerlendiren anne yüzdesi 43,9 iken gebelik sirasında bu değer \%20,2'ye düşmüştür. "Çok kötü-kötü" olarak değerlendiren gebe yüzdesi ise gebe kalmadan önce 14,5 iken, gebelik sırasında 46,0 'a yükselmiştir $(p<0,05)$ (Tablo II). Çürük ve/veya protez gerektiren eksik dişe bağlı olarak gebelerin \%90,7'sinin, diş eti hastalığı nedeniyle de $\% 56,9$ 'unun tedavi gereksinimi olduğu belirlenmiştir. Buna göre, ağız-diş sağlı̆̆ hizmeti gereksinimi olan gebe oranı \%94,4'tür. Bu gebelerin \%20,5'i hizmet gereksinimi olmasına rağmen ağız-diş sağlığını "çok iyi-iyi” olarak değerlendirmiştir. Hizmet gereksinimi olan 234 gebenin \%39,3'ü son bir y1l içinde ve sadece $\% 6$ 'sı da gebeliği sırasında diş hekimine gitmiştir. 
Tablo I. Araştırma grubunun tanımlayıcı değişkenlere göre dağılımı

\begin{tabular}{|c|c|c|c|}
\hline \multicolumn{2}{|l|}{ Değişken } & $\mathbf{n}$ & $(\%)$ \\
\hline \multirow[t]{5}{*}{ Yaş } & 18 yaş ve altı & 4 & $(1,6)$ \\
\hline & $19-24$ yaş & 81 & $(32,7)$ \\
\hline & $25-29$ yaş & 77 & $(31,0)$ \\
\hline & $30-34$ yaş & 63 & $(25,4)$ \\
\hline & 35 yaş ve üzeri & 23 & $(9,3)$ \\
\hline \multirow[t]{4}{*}{ Öğrenim durum } & Okur-yazar değil & 34 & $(13,7)$ \\
\hline & Okur-yazar ama ilkokulu bitirmemiș & 23 & $(9,3)$ \\
\hline & İlkokul & 98 & $(39,5)$ \\
\hline & Ortaokul ve üstü & 83 & $(37,5)$ \\
\hline \multirow[t]{4}{*}{ Eşinin öğrenim durumu } & Okur-yazar değil & 8 & $(3,2)$ \\
\hline & Okur-yazar ama ilkokulu bitirmemiş & 12 & $(4,8)$ \\
\hline & İlkokul & 111 & $(44,8)$ \\
\hline & Ortaokul ve üstü & 117 & $(47,2)$ \\
\hline \multirow[t]{2}{*}{ İzmir'de yaşama süresi } & 5 yıl ve üzeri & 179 & $(72,2)$ \\
\hline & 5 yıldan az & 69 & $(27,8)$ \\
\hline \multirow[t]{4}{*}{ İzmir'e gelmeden önce yaşadığı yer } & İl & 56 & $(22,6)$ \\
\hline & İlçe & 59 & $(23,8)$ \\
\hline & Köy & 73 & $(29,4)$ \\
\hline & Doğduğundan beri İzmir' de yaşıyor & 60 & $(24,2)$ \\
\hline \multirow[t]{10}{*}{ İzmir'e gelmeden önce yaşanılan bölge } & İstanbul, Batı Marmara, Doğu Marmara & 18 & $(7,2)$ \\
\hline & Ege & 29 & $(11,7)$ \\
\hline & Batı Anadolu, Orta Anadolu & 17 & $(6,8)$ \\
\hline & Akdeniz & 11 & $(4,4)$ \\
\hline & Batı Karadeniz, Doğu Karadeniz & 5 & $(2,0)$ \\
\hline & Kuzeydoğu Anadolu & 56 & $(22,6)$ \\
\hline & Ortadoğu Anadolu & 16 & $(6,5)$ \\
\hline & Güneydoğu Anadolu & 31 & $(12,5)$ \\
\hline & Yurtdışı (Suriye, Bulgaristan) & 5 & $(2,0)$ \\
\hline & Doğduğundan beri İzmir'de yaşıyor & 60 & $(24,2)$ \\
\hline \multirow[t]{3}{*}{ Anadil } & Türkçe & 184 & $(74,2)$ \\
\hline & Kürtçe & 61 & $(24,6)$ \\
\hline & Diğer (Arapça, Zazaca, Teberce) & 3 & $(1,2)$ \\
\hline \multirow[t]{4}{*}{ Çalışma durumu } & Ev Hanımı & 228 & $(91,9)$ \\
\hline & Çalışıyor & 14 & $(5,6)$ \\
\hline & İşsiz & 4 & $(1,6)$ \\
\hline & Öğrenci & 2 & $(0,8)$ \\
\hline \multirow[t]{5}{*}{ Sosyal sinif } & Kendi hesabına çalışan & 23 & $(9,3)$ \\
\hline & İşveren & 6 & $(2,4)$ \\
\hline & Beyaz yakalı & 3 & $(1,2)$ \\
\hline & Mavi yakalı & 158 & $(63,7)$ \\
\hline & İşsiz/marjinal & 58 & $(23,4)$ \\
\hline \multirow[t]{2}{*}{ Sosyal güvence } & Yok & 64 & $(25,8)$ \\
\hline & Var & 184 & $(74,2)$ \\
\hline \multirow[t]{2}{*}{ Sağlık güvencesi } & Yok & 30 & $(12,1)$ \\
\hline & Var & 218 & $(87,9)$ \\
\hline \multirow[t]{2}{*}{ Aylık gelir } & $<$ Asgari ücret & 87 & $(35,1)$ \\
\hline & $\geq$ Asgari ücret & 161 & $(64,9)$ \\
\hline \multirow[t]{2}{*}{ Aile yapısı } & Geleneksel & 69 & $(27,8)$ \\
\hline & Çekirdek & 179 & $(72,2)$ \\
\hline \multirow[t]{2}{*}{ Evde bir odaya düşen kişi sayısı } & 1'den fazla & 122 & $(49,2)$ \\
\hline & 1 ve altı & 126 & $(50,8)$ \\
\hline Toplam & & 248 & $(100,0)$ \\
\hline
\end{tabular}


Tablo II. Katılımcıların gebelik öncesinde ve gebelik sırasındaki ağıZ-diş sağllğı ile ilgili öz değerlendirmesi

\begin{tabular}{|c|c|c|c|}
\hline Ağız-diş sağlığı dü- & Gebe kalmadan önce & Gebelik sirasında & \\
\hline zeyi & $\begin{array}{ll}\text { n } & (\%)\end{array}$ & $\begin{array}{ll}\text { n } & (\%)\end{array}$ & $P a$ \\
\hline Çok iyi- iyi & $109 \quad(43,9)$ & $50 \quad(20,2)$ & 0,000 \\
\hline Orta & $103(41,5)$ & $84 \quad(33,9)$ & \\
\hline Kötü- çok kötü & $36(14,5)$ & $114 \quad(46,0)$ & \\
\hline Toplam & $248(100,0)$ & $248(100,0)$ & \\
\hline
\end{tabular}

Tablo III'te tedavi gereksinimi olan kadınlar arasında, son bir yılda diş hekimine gitme durumları ile bir dizi değişken arasındaki ilişki incelenmiştir. Buna göre, aylık hane geliri asgari ücret ve üstü olan gebelerin son bir yılda diş hekimine gitme yüzdesi daha yüksektir $(p<0,05)$. Tablo
III'teki tüm değişkenlerin hizmet kullanımı ile ilişkisi lojistik regresyon analizi ile değerlendirildiğinde; aylık geliri asgari ücret ve üstünde olan gebelerin son bir yılda diş hekimliği hizmetlerinden yararlanmış olma olasılığ gebelere göre 2,05 kat (GA=1,08 - 3,88) yüksek bulunmuştur $(p<0,05)$ (Tablo IV).

Tablo III. Ağız diş sağlığı hizmeti gereksinimi olan gebelerin sosyo-demografik ve ekonomik özelliklerine göre son bir yılda diş hekimliği hizmeti kullanımı

\begin{tabular}{|c|c|c|c|c|c|c|}
\hline & \multicolumn{6}{|c|}{ Son bir yılda diş hekimine gitme durumu } \\
\hline & \multicolumn{2}{|c|}{ Gitmiş } & \multicolumn{2}{|c|}{ Gitmemiş } & \multirow{2}{*}{$\frac{\text { Toplam }}{\mathrm{n}}$} & \multirow{2}{*}{$\frac{\text { İstatistiksel Analiz }}{p^{\text {a }}}$} \\
\hline & $\mathbf{n}$ & $(\%)$ & $\mathbf{n}$ & $(\%)$ & & \\
\hline \multicolumn{7}{|l|}{ Öğrenim durumu } \\
\hline İlkokul altı & 19 & $(33,9)$ & 37 & $(66,1)$ & 56 & 0,344 \\
\hline İlkokul ve üstü & 73 & $(41,0)$ & 105 & $(59,0)$ & 178 & \\
\hline \multicolumn{7}{|l|}{ İzmir'de yaşama süresi } \\
\hline$\leq 5$ yil & 24 & $(35,3)$ & 44 & $(64,7)$ & 68 & 0,420 \\
\hline$>5$ yil & 68 & $(41,0)$ & 98 & $(59,0)$ & 166 & \\
\hline \multicolumn{7}{|l|}{ Anadil } \\
\hline Türkçe & 68 & $(39,8)$ & 103 & $(60,2)$ & 171 & 0,816 \\
\hline Kürtçe, Arapça ve Diğerleri & 24 & $(38,1)$ & 39 & $(61,9)$ & 63 & \\
\hline \multicolumn{7}{|l|}{ Sosyal Sınıf } \\
\hline Mavi yakalı, işsiz, marjinal & 83 & $(40,3)$ & 123 & $(59,7)$ & 206 & 0,408 \\
\hline $\begin{array}{l}\text { İşveren, kendi hesabına çalışan, } \\
\text { beyaz yakalı }\end{array}$ & 9 & $(32,1)$ & 19 & $(67,9)$ & 28 & \\
\hline \multicolumn{7}{|l|}{ Sosyal Güvence } \\
\hline Var & 71 & $(40,3)$ & 105 & $(59,7)$ & 176 & 0,576 \\
\hline Yok & 21 & $(36,2)$ & 37 & $(63,8)$ & 58 & \\
\hline \multicolumn{7}{|l|}{ Sağlık Güvencesi } \\
\hline Var & 80 & $(39,2)$ & 124 & $(60,8)$ & 204 & 0,935 \\
\hline Yok & 12 & $(40,0)$ & 18 & $(60,0)$ & 30 & \\
\hline \multicolumn{7}{|l|}{ Aylık gelir } \\
\hline$<$ Asgari ücret & 24 & $(29,3)$ & 58 & $(70,7)$ & 82 & 0,021 \\
\hline$\geq$ Asgari ücret & 68 & $(44,7)$ & 84 & $(55,3)$ & 152 & \\
\hline \multicolumn{7}{|l|}{ Aile yapısı } \\
\hline Geleneksel & 23 & $(35,4)$ & 42 & $(64,6)$ & 65 & 0,445 \\
\hline Çekirdek & 69 & $(40,8)$ & 100 & $(59,2)$ & 169 & \\
\hline \multicolumn{7}{|l|}{ Evde bir odaya düşen kişi sayısı } \\
\hline $1^{\prime}$ den fazla & 42 & $(36,2)$ & 74 & $(63,8)$ & 116 & 0,334 \\
\hline 1 ve alt1 & 50 & $(42,4)$ & 68 & $(57,6)$ & 118 & \\
\hline Toplam & 92 & $(39,3)$ & 142 & $(60,7)$ & 234 & \\
\hline
\end{tabular}

*Ki-kare istatistiksel analizi p değeri 
Anne adaylarının \%58,5'i (145 gebe) gebeliğinin başından beri dişleriyle ilgili sorun yaşadığını belirtmiştir. Bu kadınların sadece \%9,7'si, yani 14 anne adayı yaşadı̆̆ı sorun için diş hekimine gidebilmiştir. Diş hekimine gitmemiş olan gebelerin belirttikleri nedenler Tablo V'te sunulmuştur. Gebelik sırasındaki diş tedavisinin bebeğine zarar vermesinden korkma ve sorunun çok önemli olmadığını düşünme en çok belirtilen nedenlerdir.

Araştırma grubundaki kadınların \%71,8'i hayatı boyunca en az bir kez diş hekimine gittiğini bildirmiştir, ama bir diş hekimi tarafından dişlerinin nasıl temizlenmesi gerektiği gösterilmiş olan kadın yüzdesi sadece $31,0^{\prime}$ dır. Herhangi bir sağlık çalışanı tarafından gebelik dönemine özel ağız-diş sağlı̆̆1 sorunları hakkında bilgilendirilmiş olma sıklığı ise \%7,3 düzeyinde kalmıştır. Araştırma tarihleri sırasındaki gebeliği dışında çocuğu olan kadınların \%41,7'si çocuğu için en az bir kez diş hekimine gittiğini belirtmiştir. Ancak çocukların ağız-diş sağlığı riskleri ve bakımı hakkında bir sağlık çalışanı tarafından bilgilendirilmiş olan kadınlar tüm çalışma grubunun sadece $\%$ 6,5'ini oluşturmuştur.

\section{TARTIŞMA}

$\mathrm{Bu}$ çalışma sosyoekonomik dezavantajların oldukça yoğun düzeyde gözlendiği bir araştırma grubunda uygulanmış ve diş hekimliği hizmetlerinin kullanımı açısından yaşanan önemli yetersizliklere işaret etmiştir. Her ne kadar sınırlı bir bölgede gerçekleştirilmiş olsa da elde edilen bulgular düşük öğrenim durumu ve gelir düzeyi, göçmen olma gibi dezavantajlar yaşayan anne adaylarının ağız-diş sağlığı hizmeti gereksinimleri ve bu hizmetlerden yararlanma düzeyleri hakkında genel bir çerçeve sunmaktadir.

Tablo IV. Ağız diş sağlığı hizmeti gereksinimi olan gebelerde lojistik regresyon analizine göre son bir yılda diş hekimliği hizmeti kullanımının belirleyicileri

\begin{tabular}{lrrr}
\hline Değişken & $\begin{array}{r}\text { Olasılıklar } \\
\text { Oranı }\end{array}$ & $\begin{array}{r}\text { \%95 Güven } \\
\text { Aralı̆̆ı }\end{array}$ & $p$ \\
\hline $\begin{array}{l}\text { Aylık gelirin asgari ücretin üstünde olması } \\
\text { (asgari ücretin altında olmasına göre) }\end{array}$ & 2,05 & $1,08-3,88$ & 0,027 \\
\hline
\end{tabular}

Lojistik regresyon analizine dahil edilen değişkenler: öğrenim durumu, İzmir'de yaşama süresi, anadil, sosyal sınıf, sosyal güvence, sağ lık güvencesi, aylık gelir, aile yapısı ve evde bir odaya düşen kişi sayısı

Tablo V. Gebeliğinde dişleriyle ilgili sorun yaşadığını söyleyen kadınların diş hekimine gidememe nedenleri

\begin{tabular}{lrr}
\hline Diş hekimine gitmeme nedeni* $^{*}$ & $\mathbf{n}$ & $\mathbf{( \% )}$ \\
\hline Gebelik sırasındaki diş tedavisinin bebeğine zarar vermesinden korkma & 52 & 39,6 \\
Sorunu çok önemli bulmama & 41 & 31,2 \\
Zaman bulamama & 13 & 9,9 \\
Diş tedavisinden korkma & 9 & 6,8 \\
Sosyal güvencenin olmaması & 5 & 3,8 \\
Diğer sağllk sorunları & 4 & 3,0 \\
Sikayetin geçmesi & 4 & 3,0 \\
Ödeme gücünün olmaması & 3 & 2,2 \\
Nereye ve nasıl başvuracağını bilmeme & 2 & 1,5 \\
Evden izin alamama & 2 & 1,5 \\
Diş hekiminin uzakta olması & 1 & 0,7 \\
\hline
\end{tabular}

*Gebelerin bir kısmı birden çok neden belirtmiştir 
Ülkemizde gebelerin ağı-diş sağlı̆̆ hizmetlerinden yararlanma düzeyini değerlendiren diğer çalışmalardan farklı olarak Bornova'da gerçekleştirilmiş olan bu çalışmaya katılan kadınların ağı-diş sağlı̆̆ı diş hekimlerinin yaptığı muayeneler aracılığı ile değerlendirilmiştir. Muayene sonuçlarına göre her on gebeden dokuzu diş tedavisine gereksinim duymaktadir. Ayrıca her iki gebeden birinde gingivitis ya da daha ileri bir diş eti hastalığı olan periodontitis saptanmıştır. Farklı çalışmalarda gebeler ve postpartum dönemdeki kadınlar için bildirilen diş eti hastalığı insidansının \%30 ila 100 arasında değiştiği dikkate alınırsa gingivitis ve periodontitis sıklığının araştırma grubunda henüz çok yüksek bir düzeyde olmadığı görülmektedir $(33,34)$. Diğer yandan literatürde karşılaşılan çalışmalara göre araştırma grubunun büyük bölümünü daha genç ve gebeliğinin başında olan kadınlar oluşturmaktadır. Bu nedenle sorunların henüz başlangıç aşamasında olduğu düşünülebilir. Bunun yanı sıra, bulgularımız çalışmaya katılan kadınların önemli bölümünün gereksinimlerinin farkında olmadığını göstermiştir. Tedavi gereksinimi olan her on kadından yaklaşık olarak beşi ağızdiş sağlığının orta düzeyde veya daha iyi olduğunu belirtmiştir.

$\mathrm{Bu}$ çalışmada gereksinim düzeyinin belirlenmesinde kullanılan bir diğer kriter anne adaylarının bildirimi olmuş ve yaklaşık iki katılımcıdan biri gebeliğinin başından beri dişleriyle ilgili herhangi bir sorun yaşadığını ifade etmiştir. Danimarka, Kuveyt ve Avustralya'da yapılan çalışmalarda gebeler arasında herhangi bir diş sağlığı sorunu yaşadığını bildirme sıklığı sırasıyla \%27, \%40 ve \%65 olarak saptanmıştır $(2,8,30)$. Buna göre farklı sosyoekonomik özellikteki ülkeler ile benzer bir durum söz konusudur. Fakat kadınlar arasındaki sorunlarını algılama düzeyi farklılıkları bu karşılaştırmayı sınırlamaktadır. Bununla birlikte, çalışmamızda ağız-diş sağlığı düzeyini "çok kötü-kötü" olarak değerlendiren kadın oranı gebelik öncesinde $\% 14,5$ iken, gebelik döneminde $\% 46,0^{\prime}$ a çıkmıştır. ABD' de yapılan bir çalışmada bildirilen sonuçlara çok yakın olan bu değerler, her ne kadar gereksinimlerini yeterince fark edemiyor olsalar da çalışmamıza katılan anne adaylarının gebelikle birlikte kendilerinin de algılayabildiği düzeyde sorunlar yaşadığını göstermektedir.

Farklı ülkelerde yapılmış pek çok çalışma kadınların yaklaşık olarak yarısının gebelikleri boyunca en az bir kez diş hekimine gittiğini göstermiştir $(2,16,35,36)$. ABD'de yapılmış iki çalışmada ise bu değerler \%23 ve \%43 olarak bildirilmiştir $(16,37)$. Wei Sun, Çin'de gebelikleri boyunca düzenli diş hekimine gitme sıklığını değerlendirmiş ve \%16,7 düzeyinde bir sıklık saptamıştır (38). Bornova'nın yoksul semtlerinde gerçekleşen bu çalışmada saptanan gebelikte diş hekimliği hizmeti alma sıklığı ise sadece $\% 6$ 'dır. Kadınların \%28,2'sinin tüm hayatı boyunca hiç diş hekimine gitmediği düşünülürse bu beklenen bir durumdur. Iowa'da yapılan bir çalışmanın sonuçları gebelik dönemindeki hizmet kullanımının gebelik öncesi kullanımdan büyük oranda etkilendiğini göstermektedir (14). Buna göre, gebelik öncesinde 6-12 ayda bir diş hekimi kontrolüne gidenlerin gebelik döneminde diş hekimine gitme olasılıkları on kat daha yüksek bulunmuştur.

Diş hekimliği hizmetleri eşitsizliklerin oldukça yoğun yaşandığı bir alandır. İsveç’te yapılan bir çalışmada bir sosyoekonomik dezavantaj indeksi geliştirilmiş ve bu indeksin her bir artan düzeyinde hem ağız sağlığının hem de hizmet kullanımının kötüleştiği saptanmıştır (39). Ayrıca birçok çalışma ağız-diş sağlığı sorunlarının yoksullarda daha yaygın olmasına karşın diş hekimliği hizmetlerine toplumun sadece sosyoekonomik açıdan avantajlı kesimlerinin erişebildiğine işaret etmiştir $(22,23)$. Aynı tablo gebelik döneminde de gözlenmektedir. Çok sayıda toplum tabanlı çalışmada gebelerin diş hekimliği hizmeti kullanımında sosyoekonomik özelliklerle bağlantılı eşitsizliklerin yaşandığı bildirilmiştir (16-18,40). Bu çalışmaların sonuçları bir araya getirildiğinde gebelerin hizmet alma davranışının; medeni durum, öğrenim durumu ve gelir düzeyi, sosyal güvence varlığı ve bu güvenceden nasıl yararlanacağını bilme, ağız sağlığına yönelik algı, hizmet sunumunun özellikleri, sağlık çalışanlarının bilgisi, diş hekimlerinin gebeleri tedavi etme konusundaki yaklaşımı gibi çok sayıda etmen tarafından şekillendirildiği görülmektedir (16-18,40-42). Fakat bu etmenlerin arasında en belirleyici rolü yoksulluğun oynadığı bilinmektedir $(14,16,43)$. Benzer şekilde Bornova'da yapılan bu çalışmada da asgari ücretin üzerinde bir aylık gelire sahip olan kadınların son bir yıl içinde en az bir kez diş hekimine gitmiş olma olasılıkları diğer kadınlardan daha yüksek bulunmuştur. 
Hizmet kullanımını etkileyen bir başka faktör ise gebelik döneminde diş tedavisi ile ilgili yanlış inanışlardır (33). Gebelerin diş hekimliği hizmetlerine ücretsiz olarak erişebildikleri ülkelerde bile bu hizmetlerin kullanımının çok düşük bir düzeyde olması bu inanışların etkisini yansıtmaktadır $(44,45)$. Türkiye'de yapılan bir çalışmaya göre gebelikte dişleriyle ilgili sorun yaşamasına rağmen diş hekimine gitmeyen gebelerin en fazla belirttikleri sebep; diş hekiminin tıp doktoruna danışmadan anestezik veya antibiyotik kullanmasından ve bunun bebeğe zarar vermesinden endişe edilmesidir. Benzer şekilde bu çalışmada da gebeliğinde dişleriyle ilgili sorun yaşayan her beş gebeden ikisi gebelik sırasındaki diş tedavisinin bebeğine zarar vereceği inancına sahip olduğu için diş hekimine gitmediğini açıklamıştır. Belirtilen diğer nedenler ise İngiltere'de yapılan bir çalışmada olduğu gibi sorunu çok önemli bulmama ve diş hekiminden korkmadır (46).

Araştırmaya katılan kadınların ağız-diş sağlığı ile ilgili bilgilendirilme düzeyi değerlendirildiğinde oldukça çarpıcı bulgular ile karşılaşılmıştır. Kadınların sadece \%7,3'ü kendisine herhangi bir sağlık çalışanı tarafından gebelik dönemine özgü ağız-diş sağlığı riskleri hakkında bilgi verildiğini bildirmiştir. Çocukların ağız bakımı hakkında bilgi almış olan kadınlar ise araştırma grubunun sadece \%6,5'ini oluşturmuştur. Farklı çalışmalarla karşılaştırıldığında Bornova çalışmasındaki bilgilendirilme düzeyinin ne kadar yetersiz olduğu daha iyi anlaşılmaktadır. Iowa'da yapılan bir çalışmada kadınların \% 32'sine bir tıp doktorunun, \%54'üne bir diş hekiminin, Kuveyt'te ise \%22'sine herhangi bir sağlık çalışanının gebelik dönemindeki ağız-diş sağlığına yönelik bilgi verdiği belirtilmiştir $(2,14)$. Bornova'da saptanmış olan bu çok ciddi düzeydeki yetersizliğin ülkemizin diğer bölgeleri açısından geçerli olmadığını düşündürecek herhangi bir neden yoktur. Bu nedenle bu hizmet açı̆̆ının nasıl karşılanması gerektiği en kısa zamanda planlanmalıdır. Sadece ağız-diş sağlığına yönelik eğitim kampanyalarının önemli ama tek başına yetersiz olduğu bildirilmektedir (25). Habashneh'in önerdiği gibi bu eğitimlerin kadın doğum uzmanlarının, aile hekimlerinin ve ebelerin doğum öncesi bakım hizmetlerine entegre edilmesi ve bu sayede ağı-diş sağlı̆̆ hizmetlerinin tüm kadınlara ulaşacak bir sistematik içinde verilmesi daha uygun bir yaklaşım olacaktır (14).

\section{SONUÇ}

Araştırma bulguları anne adaylarının ağız-diş sağlı̆̆ sorunlarının son derece yaygın olduğunu, buna karşın hizmet gereksinimlerinin karşılanmadığını ortaya koymuştur. Diş hekimliği hizmetlerinden yararlanma açısından gelir düzeyine bağlı bir eşitsizlik vardır. Ayrıca gebelikteki ağızdiş sağlığına yönelik bilgilendirilme açı̆̆ı çarpıcı bir düzeydedir. Gebelik dönemi boyunca kadınların ağız-diş sağlığı gereksinimlerinin karşılanmasına yönelik ücretsiz ve eşit hizmetler sunulmalı ve ağız-diş sağlığı eğitimi doğum öncesi bakım hizmetlerinin bütüncül bir bileşeni olmalıdir.

\section{KAYNAKLAR}

1. Gökalp S, Güçiz Doğan B. Türkiye Ağız-Diş Sağlığı Profili 2004. 2. Basım. Hacettepe Üniversitesi Yayınları. Hacettepe Üniversitesi Hastaneleri Basımevi; 2009.

2. Honkala S, Al-Ansari J. Self-reported oral health, oral hygiene habits, and dental attendance of pregnant women in Kuwait. J Clin Periodontol 2005;32:809-814.

3. Taani DQ, Habashneh R, Hammad MM, Batieha A. The periodontal status of pregnant women and its relationship with socio-demographic and clinical variables. J Oral Rehabil 2003;30:440-445.

4. Nuamah I, Annan BD. Periodontal status and oral hygiene practices of pregnant and non-pregnant women. East Afr Med J 1998;75:712-714.

5. Ferris GM. Alteration in female sex hormones: their effect on oral tissues and dental treatment. Compendium 1993;14:1558-64, 1566; quiz 1571.

6. American Dental Association, Council on Access, Prevention, and Interprofessional Relations 2006. Women's oral health issues.

7. Armitage GC. Bi-directional relationship between pregnancy and periodontal disease. Periodontol 2000 2013;61:160-176.

8. Christensen LB, Jeppe-Jensen D, Petersen PE. Selfreported gingival conditions and self-care in the oral health of Danish women during pregnancy. J Clin Periodontol 2003;30:949-953.

9. Jeffcoat MK, Geurs NC, Reddy MS, Cliver SP, Goldenberg RL, Hauth JC. Periodontal infection and preterm birth: results of a prospective study. J Am Dent Assoc 
2001;132:875-880.

10. López NJ, Smith PC, Gutierrez J. Periodontal therapy may reduce the risk of preterm low birth weight in women with periodontal disease: a randomized controlled trial. J Periodontol 2002;73:911-924.

11. Xiong X, Buekens P, Fraser WD, Beck J, Offenbacher S. Periodontal disease and adverse pregnancy outcomes: a systematic review. BJOG 2006;113:135-143.

12. Offenbacher S, Lieff S, Boggess KA, et al. Maternal periodontitis and prematurity. Part I: Obstetric outcome of prematurity and growth restriction. Ann Periodontol 2001;6:164-174.

13. Jeffcoat MK, Hauth JC, Geurs NC, et al. Periodontal disease and preterm birth: results of a pilot intervention study. J Periodontol 2003;74:1214-1218.

14. Al Habashneh R, Guthmiller JM, Levy S, et al. Factors related to utilization of dental services during pregnancy. J Clin Periodontol 2005;32:815-821.

15. Boggess KA, Lieff S, Murtha AP, Moss K, Beck J, Offenbacher S. Maternal periodontal disease is associated with an increased risk for preeclampsia. Obstet Gynecol 2003;101:227-231.

16. Gaffield ML, Gilbert BJ, Malvitz DM, Romaguera R. Oral health during pregnancy: an analysis of information collected by the pregnancy risk assessment monitoring system. J Am Dent Assoc 2001;132:1009-1016.

17. Marchi KS, Fisher-Owen SA, Weintraub JA, Yu Z, Braveman PA. Most pregnant women in California do not receive dental care: findings from a population-based study. Public Health Rep 125:831-842.

18. Boggess KA, Urlaub DM, Massey KE, Moos M-K, Matheson MB, Lorenz C. Oral hygiene practices and dental service utilization among pregnant women. J Am Dent Assoc 2010;141:553-561.

19. Sgan-Cohen HD, Mann J. Health, oral health and poverty. J Am Dent Assoc 2007;138:1437-1442.

20. Edelstein BL, Chinn CH. Update on disparities in oral health and access to dental care for America's children. Acad Pediatr 9:415-419.

21. Geyer S, Schneller T, Micheelis W. Social gradients and cumulative effects of income and education on dental health in the Fourth German Oral Health Study. Community Dent Oral Epidemiol 2010;38:120-128.
22. Grytten J, Lund E, Rongen G. Equity in access to public dental services: the experience from Norway. Acta Odontol Scand 2001;59:372-378.

23. Nguyen L, Häkkinen U. Choices and utilization in dental care: Public vs. private dental sectors, and the impact of a two-channel financed health care system. Eur J Health Econ 2006;7:99-106.

24. Petersen PE. The World Oral Health Report 2003: continuous improvement of oral health in the 21 st century - the approach of the WHO Global Oral Health Programme. Community Dent Oral Epidemiol 2003;31:324.

25. Chung LH, Gregorich SE, Armitage GC, Gonzalez-Vargas J, Adams SH. Sociodemographic disparities and behavioral factors in clinical oral health status during pregnancy. Community Dent Oral Epidemiol 2014;42:151-159.

26. Carl DL, Roux G, Matacale R. Exploring dental hygiene and perinatal outcomes. Oral health implications for pregnancy and early childhood. AWHONN Lifelines 4:2227.

27. Raber-Durlacher JE, van Steenbergen TJ, Van der Velden U, de Graaff J, Abraham-Inpijn L. Experimental gingivitis du-ring pregnancy and post-partum: clinical, endocrinological, and microbiological aspects. J Clin Periodontol 1994;21:549-558.

28. Tarsitano BF, Rollings RE. The pregnant dental patient: evaluation and management. Gen Dent 41:226-34;233-234.

29. Armitage GC. Development of a classification system for periodontal diseases and conditions. Ann Periodontol 1999;4:1-6.

30. Thomas NJ, Middleton PF, Crowther CA. Oral and dental health care practices in pregnant women in Australia: a postnatal survey. BMC Pregnancy Childbirth 2008;8:13.

31. Boratav K. İstanbul ve Anadolu'dan Sinıf Profilleri. 2. Baskı. İstanbul: İmge Kitabevi; 2004.

32. Belek İ. Sosyoekonomik Konumda ve Sağlıkta Sınıfsal Eşitsizlikler. Antalya’da Beş Yıllık Bir Araştırma. Ankara: TTB Yayınları; 2004.

33. Ozen B, Ozer L, Bașak F, Altun C, Açıkel C. Turkish women's self-reported knowledge and behavior towards oral health during pregnancy. Med Princ Pract 2012;21:318-322.

34. Cornejo C, Rossi G, Rama A, et al. Oral health status and 
oral health-related quality of life in pregnant women from socially deprived populations. Acta Odontol Latinoam 2013;26:68-74.

35. Lydon-Rochelle MT, Krakowiak P, Hujoel PP, Peters RM. Dental care use and self-reported dental problems in relation to pregnancy. Am J Public Health 2004;94:765771 .

36. Singhal A, Chattopadhyay A, Garcia AI, Adams AB, Cheng D. Disparities in unmet dental need and dental care received by pregnant women in Maryland. Matern Child Health J 2014;18:1658-1666.

37. Mangskau KA, Arrindell B. Pregnancy and oral health: utilization of the oral health care system by pregnant women in North Dakota. Northwest Dent 75:23-28.

38. Sun W, Guo J, Li X, Zhao Y, Chen H, Wu G. The routine utilization of dental care during pregnancy in eastern China and the key underlying factors: a Hangzhou City study. PLoS One 2014;9:98780.

39. Wamala S, Merlo J, Boström G. Inequity in access to dental care services explains current socioeconomic disparities in oral health: the Swedish National Surveys of Public Health 2004-2005. J Epidemiol Community Health 2006;60:1027-1033.

40. Hwang SS, Smith VC, McCormick MC, Barfield WD. Racial/ethnic disparities in maternal oral health experiences in 10 states, pregnancy risk assessment monitoring system, 2004-2006. Matern Child Health J 2011;15:722-729.

41. Le M, Riedy C, Weinstein P, Milgrom P. Barriers to utilization of dental services during pregnancy: a qualitative analysis. J Dent Child (Chic) 76:46-52.

42. Kloetzel MK, Huebner CE, Milgrom P, Littell CT, Eggertsson H. Oral health in pregnancy: educational needs of dental professionals and office staff. J Public Health Dent 2012;72: 279-286.

43. Watson MR, Gibson G, Guo I. Women's oral health awareness and care-seeking characteristics: a pilot study. J Am Dent Assoc 1998;129:1708-1716.

44. Dinas K, Achyropoulos V, Hatzipantelis E, et al. Pregnancy and oral health: utilisation of dental services during pregnancy in northern Greece. Acta Obstet Gynecol Scand 2007;86:938-944.

45. Hullah E, Turok Y, Nauta M, Yoong W. Self-reported oral hygiene habits, dental attendance and attitudes to dentistry during pregnancy in a sample of immigrant women in North London. Arch Gynecol Obstet 2008;277:405409.

46. Rogers SN. Dental attendance in a sample of pregnant women in Birmingham, UK. Community Dent. Health 1991;8:361-368. 